\title{
FERRELL, Jeff; HAYWARD, Keith; MORRISON, Wayne; PRESDEE, Mike eds., Cultural Criminology Unleashed. (Londres: GlassHousshouse Press, 2004. 336 p.)
}

\section{Maria Gabriela Seibel ${ }^{1}$}

A Criminologia Cultural representa uma esfera de conhecimento cujos horizontes teóricos e práticos assumem características mosaicas de abordagens interdisciplinares que dialogam e se sobrepõem. Foi formalmente introduzida em 1995, através do livro Cultural Criminology, uma compilação de ensaios editada por Ferrell e Sanders (1995), e pode-se dizer que vem delineando-se como uma rede em que diversas forças se encontram, interagem entre si, e a partir da qual voltam a propagar-se para outros pontos. Busca penetrar a zona nebulosa de convergência onde comportamento coletivo - manifesto em dinâmicas culturais e estilo - encontra-se, confunde-se, ou mesmo é a performance de crime e desvio.

Lançado em 2004, o livro Cultural Criminology Unleashed é posterior a outros títulos que contribuíram fundamentalmente para a pavimentação dos caminhos iniciais da Criminologia Cultural nas Ciências Sociais. Portanto, distanciando-se de traços introdutórios, o que Cultural Criminology Unleashed comunica é a intenção dos autores e editores de "libertarem" a Criminologia Cultural, de proporcionarem um espaço para a interação de diferentes perspectivas e provocações que não necessariamente concordem entre si, mas que se desvinculem ainda mais dos pressupostos da criminologia tradicional.

O volume é uma compilação de vinte e quatro ensaios arranjados em seis seções temáticas que, simplificadamente, correspondem a: (1) teoria, (2) questões internacionais e relações culturais, (3) oposição ao essencialismo de imagens marginais, (4) espaço da cidade e suas relações, (5) relações em pesquisa de campo e metodologia e (6) agência e controle.

\footnotetext{
${ }^{1}$ Universidade Feevale, Brasil.
} 


\section{Parte 1: Teoria}

$\mathrm{Na}$ parte inicial, Jock Young nos convida a pensar em como narrativas e interposições de subjetividades de atores sociais podem levar a resoluções diferentes das que considerações de situações materiais, biológicas ou sociais pudessem, isoladamente, sugerir. Desse modo, o autor estrutura uma crítica às pesquisas feitas com metodologias quantitativas, especialmente aos métodos estatísticos, questionando as posturas de imparcialidade e veracidade que tentam transmitir através da suposta objetividade dos resultados obtidos e expressos em números. Young afirma que esses métodos afastam os criminologistas do crime enquanto fenômeno real. Mais adiante, Mike Presdee reitera a crítica, ressaltando o caráter emocional, a permeação simbólica e as histórias que compõem os "números", trazendo suas perspectivas pessoais e atentando para o caráter emblemático do estilo nas manifestações de crime e desvio. Ao associarmos os dois textos, evidenciamos que os dois autores apontam para a necessidade da observação participante e adoção de métodos etnográficos para o melhor entendimento dos comportamentos desviantes. Ambos baseiam suas conclusões na inviabilidade de uma sociologia positivista do crime, na diversidade de definições de crime e graus de violência, e propõem a suspensão do processo de categorização fixado a priori.

Ainda nessa seção, Tony Jefferson apresenta abordagens psicossociais a partir das quais trata de masculinidade e crime. Jefferson apresenta o sujeito masculino em situações estáveis e de poder como autor de crimes, ao associar características que estereotipicamente são atribuídas a sujeitos constituídos por discursos diferentes, uma revisão acerca de um tipo de categorização é proposta. Ao relacionar as imposições de poder às ideias de regime de verdade, assujeitamento, análise de discurso e estudos culturais, Jefferson exerce o papel de contestação e crítica que deu origem à Criminologia Cultural. Em seguida, Jonathan Wender defende uma abordagem holística e enfoque fenomenológico para a percepção de crime e desvio. Por fim, Jeff Ferrell trata da relevância do estilo enquanto meio simbólico através do qual grupos em desvantagem e autoridades interagem. 


\section{Parte 2: Questões internacionais e relações culturais}

No ensaio de Wayne Morrison, encontramos uma apresentação do museu de Lombroso enquanto alegoria à criminologia tradicional e representação do positivismo como fenômeno cultural. O caráter provocativo do texto propõe o reconhecimento dos poderes que permeiam e orientam diversas pesquisas e teorias através da história, salientando afirmações etnocêntricas e tendenciosas de Lombroso com o intuito de ilustrar eventuais perigos a que estão sujeitas as tentativas de impor às ciências sociais a mesma tenacidade das bases epistemológicas que sustentam as ciências naturais. Dessa forma, o autor traça uma oposição à "naturalização" da criminologia: à medida em que o crime é permeado de significações culturais, quaisquer tentativas de imposições lógicas que o definam universalmente são inconcebíveis. Uma vez que a definição de crime e sua performance são entendidos pela Criminologia Cultural enquanto interação e exercício de poder e resistência, o risco de transformá-lo em fato plano consiste em negar sua complexidade e caráter simbólico em detrimento de reducionismos que levam a pouco ou nenhum entendimento a seu respeito e das dinâmicas sociais em que foram observados. A planificação de fatos culturais advém de imposições positivistas pela negação do caráter subjetivo das interações humanas, e acabam por rotular manifestações de desvio e criminalidade de forma patológica, impondo distanciamentos do social, podendo resultar na marginalização e rotulação de "criminosos" e da própria noção de crime, como se fossem alheios e não merecessem ser analisados em conjunto à sociedade da qual provêm e da qual fazem parte. O que Morrison defende é que as ciências sociais evitem aderir a tais orientações e sejam sensíveis às complexidades que envolvem as interações humanas, pois quando há distanciamento, isolamento, patologização e negação de subjetividades, as relações de alteridade tornam-se hostis e excludentes.

Acerca do multiculturalismo em sociedades cosmopolitas, Frank Bovenkerk e Yucel Yesilgöz questionam quão jurídica, social e culturalmente proveitosos são os recortes étnicos em resoluções forenses. Defendem os autores que as situações sempre sejam analisadas de forma cautelosa, atentando tanto para adaptações cabíveis em casos em que as ideias particulares de minorias étnicas sobre crimes e punições divirjam das que vigoram no país em que se encontram, tanto para os casos em que o princípio da imparcialidade seja mantido no julgamento de crimes que não circunscrevam cultura ou 
distanciamentos interpretativos por ela mediados. Em seu capítulo, Chris Cunnen e Julie Stubbs tratam sobre gênero e raça através da exposição de sua etnografia de espaços virtuais para relacionamentos. No referido espaço, mulheres das Filipinas, em situação de vulnerabilidade socioeconômica, buscavam por parceiros para relações amorosas estáveis. Os autores salientam que muitos sites similares funcionam como iscas para turismo sexual e, atraindo homens de posições socioeconômicas mais elevadas e de culturas ocidentais, muitas mulheres futuramente tornaram-se vítimas dos parceiros. $\mathrm{O}$ texto ressalta concepções etnocêntricas de homens de países desenvolvidos de cultura ocidental em relação àquelas mulheres, e a vigência de um imaginário no qual mulheres asiáticas são vistas como submissas e passivas, sujeitas às imposições e violências que os homens ocidentais que as "acolhem" eventualmente queiram infligir-lhes. É digno de nota que, nesse ponto, a criminologia cultural volta-se à vitimização: como fatores culturais "constroem” vítimas de crimes.

Encerrando essa divisão de capítulos, Chris Greer trata do papel dos veículos de comunicação de massa na construção do imaginário coletivo acerca de criminosos, crimes e vítimas e da utilização de espaços virtuais para expressão de luto, raiva e demais sentimentos de forma intensa e efêmera. Seu texto direciona a reflexão a respeito das comoções em massa em resposta a tragédias envolvendo personalidades famosas em contraposição a descaso aos que se encontram fisicamente próximos mas que são "desconhecidos" em função de processos de distanciamento e marginalização como o que foi referido anteriormente.

\section{Parte 3: Oposição ao essencialismo de imagens marginais}

Um dos apontamentos recorrentes em Criminologia Cultural enquanto crítica às práticas das sociedades pós-modernas envolve o fato de que crime vende. Nesse sentido, Karin Schonfield disserta sobre a comercialização do crime no que diz respeito a programas de televisão que veiculam documentários e encenações de crimes, descrevendo e detalhando os erros determinantes cometidos por criminosos. Schonfield adere à tese de que esse tipo de programa exerça influência em outros indivíduos, no sentido de incitá-los a refazer a trajetória daqueles criminosos com o intuito de não serem pegos (ideia que vai ao encontro da interpretação do crime enquanto fonte de satisfação e riscos). Partindo dessa concepção, a autora se propõe à investigação do 
comércio virtual de imagens de crianças realizado entre pedófilos. Schonfield defende a importância de seu trabalho para melhor compreensão dessas práticas e mesmo como facilitador do encontro dos possíveis envolvidos, e frisa a necessidade de métodos etnográficos para desempenhá-lo de forma que permita assimilar o possível "estilo" justamente através daquilo que pedófilos tentam ocultar.

Nos capítulos que seguem, Kenneth D Tunnell trata sobre estereótipos envolvendo usuários de drogas vindos de regiões interioranas e Stephen L Muzzatti disserta sobre a função do medo como regulador social quando aqueles em posição de poder ambicionam condutas controláveis. A esse exemplo, Muzzatti descreve subculturas góticas, especialmente observada entre jovens, e explica que o mecanismo de imposição de medo opera por contenção dessas subculturas, inviabilizando sua possibilidades de resistência por intermédio da supressão de manifestações dissonantes.

\section{Parte 4: Espaço da cidade e suas relações}

No capítulo de abertura, Keith Hayward escreve sobre as dinâmicas de exclusão que permeiam a construção da cidade: condomínios fechados abrigando os que podem pagar por eles e garantindo o isolamento daqueles que não podem. Sobre lugares de passagem e caminhos que conectam espaços, Hayward argumenta que constituam lugares com significado para aqueles que estão isolados pela dinâmica da cidade e não podem ocupar os espaços a que conduzem. Em seguida, Jeff Ferrell trata do acúmulo de "lixo" oriundo do consumismo desenfreado em cidades capitalistas, assinalando a função socioambiental dos catadores, que dão outros destinos e funções aos materiais que coletam: reaproveitando-os, atribuindo-lhes novos significados e empregando-os em novas histórias. Ferrell fala sobre a dinâmica de exclusão dar origem a um mundo escondido, marginal: uma zona de intersecção ambígua e socialmente funcional entre a propriedade privada e a necessidade pública dos marginalizados.

Acerca da arte de rua, Heitor Alvelos descreve como o emprego do grafite em campanhas publicitárias estremecem as conexões do grafite autêntico com ideias de resistência e transgressão. Segundo Alvelos, modelos comercializados não podem ser concomitantemente empregados para resistência, de modo que é preciso encontrar novos modos de expressão e para escapar dessas redes de apropriação. 
A quarta parte é finalizada com o texto de Mark Fenwick sobre a criação do imaginário de crimes e incitação de medo, no Japão. Medo que origina-se em falas políticas sobre índices de criminalidade com o intuito de promover mobilização popular. Fenwick aponta que causem projeções dissociadas da realidade, culminando em hostilidade, perigo e demonização daqueles que já são marginalizados, especialmente em cidades pequenas.

\section{Parte 5: Relações em pesquisa de campo e metodologia}

Em seu ensaio, Fiona Measham articula-se acerca das drogas ilícitas e álcool, argumentando que sejam consideradas sua disponibilidade, as razões pelas quais são utilizadas, quais drogas são usadas por quais segmentos populacionais e questionando a função da droga enquanto fuga da sociedade de consumo uma vez que têm sido assimiladas como objetos para consumo. Measham frisa a importância da compreensão da agência das pessoas que utilizam e das questões ontológicas por trás do uso dessas substâncias, identificando na Criminologia Cultural um campo saudável para o debate de tais considerações.

Aplicando o método que chama ethno-mimesis no contexto da prostituição, Maggie O’Neill intersecciona arte performática com etnografia ao escrever sobre etnografia visual e observação participante, defendendo, com influência da teoria crítica, que os pesquisadores devem comprometer-se com a mudança das situações de injustiças que encontram em campo. De volta à concepção do crime enquanto busca por adrenalina e emoções, Curtis Jackson-Jacobs relata sua experiência com homens jovens que envolviam-se em brigas só pelo prazer e pelas emoções que o ato de brigar lhes trazia. O encerramento desse segmento se dá no mesmo viés, com Heli Vaaranen apresentando fragmentos de seu trabalho de campo com corridas clandestinas de carro.

\section{Parte 6: Agência e controle}

A sexta e última parte do livro inicia-se com o texto de questionamento de Jeff Ferrell sobre a formulação e manutenção de políticas proibicionistas contra drogas psicotrópicas, que dificulta até mesmo o debate a seu respeito, ao passo que são autorizados tanto a publicidade e o comércio de carros com referência à alta velocidade, 
máquinas que figuram em diversas mortes de trânsito, intoxicam o ambiente e conduzem às dinâmicas de reestruturação das cidades de modo a isolar e individualizar seus habitantes. Em seguida, David C. Brotherton descreve gangues enquanto grupos de interação social e frisa a importância da imaginação sociológica para os pesquisadores que queiram interagir com esses grupos, de modo a fugir de lugares-comuns que culminem em quantificações e nenhum entendimento da dinâmica social. Em seu texto, Steve Hall e Simon Winlow atentam para a importância de uma Criminologia Cultural situada histórica e socioeconomicamente, lembrando que a cultura não pode ser percebida e entendida como manifestação alheia a esses outros fatores pertinentes às interações humanas e sociais. Encerando a seção e o livro, o texto de Mark S Hamm critica as ofensivas "antiterroristas" adotadas por Bush após os eventos de 11 de setembro de 2001, nos Estados Unidos. Hamm descreve a política de medo adotada para que as medidas fossem aceitas pelo povo e criticamente aponta como comodidade o ato de determinar medidas como "sigilosas" ao passo que se alimenta pânico na população e pede por seu apoio e adesão, opondo-se também ao maniqueísmo utilizado pelo governo, o que expressa ao citar frases empregadas pelo então presidente dos Estados Unidos.

\section{Conclusões e provocações}

Os textos que dão corpo a Cultural Criminology Unleashed provêm de diversos pesquisadores. Entretanto, é possível observar que a maior parte deles são professores universitários, criminologistas e sociólogos, e que a maioria baseia-se ou na Europa (especialmente Reino Unido) ou nos Estados Unidos, o que confere ao grupo uma certa homogeneidade. Também pode-se observar que dos vinte e seis colaboradores, apenas seis autoras são mulheres, o que, irônica e infelizmente, indica pouca representatividade feminina no próprio grupo de autores que pretende questionar oligarquias culturais e estruturas de poder histórica e culturalmente fixadas. Em relação aos textos, pode-se observar que nenhum dos autores menciona as implicâncias éticas que permeiam a etnografia de comunidades e espaços a que se referem, a exemplo de acordos como o de não poder reportar à polícia pessoas que acolhem o pesquisador (Yates, 2004). Como ressaltado, apenas um texto versa sobre o processo de vitimização, centrando-se no 
sujeito feminino, ao passo que a grande maioria dos ensaios que tratam da conexão do crime com sentimentos de satisfação e adrenalina, focam-se em sujeitos masculinos.

Os pontos aqui abordados são pertinentes à Criminologia Cultural e, ao que parece, não foram suficientemente dissociados de perspectivas tradicionais, como pretendia a obra. No entanto, essa crítica não é feita com o intuito de condenar a relevância do livro. Absolutamente. Na verdade, o que propõe não destoa da ideia incitada pelos próprios editores do livro: provocar. A crítica é feita com o intuito de instigar pensamentos acerca da Criminologia Cultural: para que novos pontos se encontrem na rede aludida no início do texto e a partir dela se dissipem em novas direções de questionamentos e análises que contemplem intersecções culturais. Uma vez que a Criminologia Cultural foi declarada "liberta", seria contraditória qualquer tentativa de interceptar estradas futuras para as quais seja encaminhada.

\section{Referências}

FERREL, J.; SANDERS, C.R. (eds.), Cultural Criminology, Boston: Northeastern University Press, 1995.

YATES, J. Criminological Ethnography: Risks, Dilemmas and their Negotiation, British Journal of Community Justice 3(1), pp.19-31, 2004

Recebido em: 17/03/2015

Aprovado em: 19/05/2015 